\title{
A Simple Enzymatic Method for Production of a Wide Variety of D-Amino Acids Using L-Amino Acid Oxidase from Rhodococcus sp. AIU Z-35-1
}

\author{
Kimiyasu Isobe, ${ }^{1}$ Hiroshi Tamauchi, ${ }^{1}$ Ken-ichi Fuhshuku, ${ }^{2}$ Shouko Nagasawa, ${ }^{1}$ \\ and Yasuhisa Asano ${ }^{2}$ \\ ${ }^{1}$ Department of Biological Chemistry and Food Science, Faculty of Agriculture, Iwate University, 3-18-8 Ueda, \\ Morioka 020-8550, Japan \\ ${ }^{2}$ Biotechnology Research Center and Department of Biotechnology, Toyama Prefectural University, 5180 Kurokawa, Imizu, \\ Toyama 939-0398, Japan
}

Correspondence should be addressed to Kimiyasu Isobe, kiso@iwate-u.ac.jp

Received 14 April 2010; Revised 14 June 2010; Accepted 6 July 2010

Academic Editor: Roberto Fernandez Lafuente

Copyright (C) 2010 Kimiyasu Isobe et al. This is an open access article distributed under the Creative Commons Attribution License, which permits unrestricted use, distribution, and reproduction in any medium, provided the original work is properly cited.

\begin{abstract}
A simple enzymatic method for production of a wide variety of $\mathrm{D}$-amino acids was developed by kinetic resolution of DL-amino acids using L-amino acid oxidase (L-AAO) with broad substrate specificity from Rhodococcus sp. AIU Z-35-1. The optimum pH of the L-AAO reaction was classified into three groups depending on the L-amino acids as substrate, and their respective activities between $\mathrm{pH} 5.5$ and 8.5 accounted for more than $60 \%$ of the optimum activity. The enzyme was stable in the range from $\mathrm{pH} 6.0$ to 8.0 , and approximately $80 \%$ of the enzyme activity remained after incubation at $40^{\circ} \mathrm{C}$ for $60 \mathrm{~min}$ at $\mathrm{pH} 7.0$. D-Amino acids such as D-citrulline, D-glutamine, D-homoserine or D-arginine, which are not produced by D-aminoacylases or D-hydantoinases, were produced from the racemic mixture within a 24 -hr reaction at $30^{\circ} \mathrm{C}$ and $\mathrm{pH}$ 7.0. Thus, the present method using L-AAO was versatile for production of a wide variety of $\mathrm{D}$-amino acids.
\end{abstract}

\section{Introduction}

D-Amino acids are useful raw materials for production of pharmaceuticals and agrochemicals. At present, some Damino acids are produced by enzymatic methods on an industrial scale. For example, p-hydroxy-D-phenylglycine and $\mathrm{D}$-phenylglycine are produced by the combination of D-hydantoinase and $\mathrm{N}$-carbamyl-D-amino acid amidohydrolase [1-3]. D-Leucine, D-phenylalanine and Dmethionine can be produced by an enzymatic resolution of $\mathrm{N}$-acetyl-DL-leucine, $\mathrm{N}$-acetyl-DL-phenylalanine and $\mathrm{N}$ acetyl-DL-methionine, respectively, using bacterial $\mathrm{N}$-acylD-amino acid deacylase (EC 3.5.1.81, D-aminoacylase) [46]. D-Valine is also produced by an enzymatic resolution of $\mathrm{N}$-acetyl-DL-valine with D-aminoacylase from Defluvibacter sp. A131-3 [7]. Methods for the production of D-alanine, D-methionine, D-norvaline, D-norleucine or D-phenylalanine were demonstrated using new enzymes such as D-stereospecific aminopeptidases (EC 3.4.11.19, Daminopeptidase) [8] or D-stereoselective amino acid amidases [9-11]. The production methods of D-glutamic acid, D-proline or D-homoserine were also demonstrated using selective degradation of the corresponding L-isomer in a racemic mixture [12-14]. These enzymatic methods are useful tools for production of some $\mathrm{D}$-amino acids, but not always useful for production of a wide variety of $\mathrm{D}$-amino acids because of their limited substrate specificity. Recently, we isolated a new bacterial strain, Rhodococcus sp. AIU Z-351, for production of $N \alpha$-benzyloxycarbonyl-L-aminoadipic acid (N $\alpha$-Z-L-AAA) from $N \alpha$-benzyloxycarbonyl-L-lysine (N $\alpha$-Z-L-lysine) [15]. In the analysis of this reaction, it was demonstrated that $N \alpha$-Z-L-lysine was converted to $N \alpha$-Z-L-AAA via $N \alpha$-benzyloxycarbonyl-L-aminoadipate- $\delta$ semialdehyde ( $N \alpha-Z$-L-AASA), and the conversion of $N \alpha$ Z-L-lysine into $N \alpha$-Z-L-AASA was catalyzed by a L-specific amino acid oxidase (L-AAO) with broad substrate specificity 
[16]. Thus, the L-AAO catalyzed an oxidative deamination of $N \alpha$-acyl-L-lysine, $N \varepsilon$-acyl-L-lysine, L-lysine and many other L-amino acids, but not of $N \alpha$-acyl-D-lysine, $N \mathcal{E}$-acyl-Dlysine and $\mathrm{D}$-amino acids. These results indicate that $\mathrm{L}-\mathrm{AAO}$ produced by Rhodococcus sp. AIU Z-35-1 may be applicable for production of a wide variety of D-amino acids from DL-amino acids by kinetic resolution. The present paper describes an enzymatic method for production of $\mathrm{D}$-amino acids, which are difficult to produce by the D-aminoacylases, D-hydantoinases or D-amino acid amidases, using L-AAO from Rhodococcus sp. AIU Z-35-1.

\section{Materials and Methods}

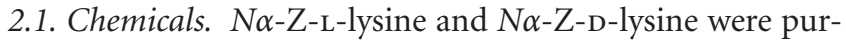
chased from Watanabe Chemical Industries (Hiroshima, Japan). D- and L-Glutamine, D- and L-arginine, D- and L-citrulline, $\mathrm{D}$ - and $\mathrm{L}$-homoserine and other amino acids were from Wako Pure Chemicals (Osaka, Japan). All other chemicals used were of analytical grade and were purchased commercially. The L-AAO from Rhodoccocus sp. Z-35-1 was purified according to our method described in a previous report [16].

2.2. Assay of Enzyme Activity. L-AAO activity was assayed by measuring the rate of hydrogen peroxide formation as follows. The standard reaction mixture contained $40 \mu \mathrm{mol}$ of L-lysine, $0.6 \mu \mathrm{mol}$ of 4 -aminoantipyrine, $1.94 \mu \mathrm{mol}$ of $N$ ethyl- $N$-(2-hydroxy-3-sulfopropyl)-3-methylaniline sodium salt dihydrate, 6.7 units of peroxidase, $0.1 \mathrm{mmol}$ of potassium phosphate, $\mathrm{pH} 7.0$, and an appropriate amount of enzyme, in a final volume of $1.0 \mathrm{ml}$. The hydrogen peroxide formation was spectrophotometrically followed at $30^{\circ} \mathrm{C}$ by measuring absorbance at $555 \mathrm{~nm}$. One unit (U) is the amount of enzyme that catalyzes the formation of one micromole of hydrogen peroxide from L-lysine per min.

2.3. Assay of Optimum $p H$ and $p H$ Stability. Optimum $\mathrm{pH}$ of L-AAO activity was analyzed under standard assay conditions, except that the reaction $\mathrm{pH}$ values were varied between 5.0 and 8.5 by $0.1 \mathrm{mmol}$ of acetate buffer, $\mathrm{pH} 5.0$ 5.5 or $0.1 \mathrm{mmol}$ of potassium phosphate, $\mathrm{pH}$ 5.5-8.5. The $\mathrm{pH}$ stability of L-AAO was analyzed by assaying the residual activity after incubation with $50 \mathrm{mM}$ potassium phosphate, $\mathrm{pH} 5.5-8.5$, at $40^{\circ} \mathrm{C}$ for $60 \mathrm{~min}$. The thermal stability of L-AAO was analyzed by assaying the residual activity after incubation with $50 \mathrm{mM}$ potassium phosphate, $\mathrm{pH} 7.0$, at 30$60^{\circ} \mathrm{C}$ for $60 \mathrm{~min}$.

2.4. Standard Reaction of L-Amino Acid Oxidation and DAmino Acid Production. L-Amino acid oxidation was carried out by incubation of 20 micromoles of $\mathrm{L}$-amino acids with $15.5 \times 10^{-3} \mathrm{U}$ of $\mathrm{L}-\mathrm{AAO}$ at $30^{\circ} \mathrm{C}$ for $24 \mathrm{hr}$ in $1 \mathrm{ml}$ of $0.1 \mathrm{M}$ potassium phosphate buffer, $\mathrm{pH}$ 7.0, containing 1700 units of catalase with shaking at $120 \mathrm{rpm}$. Production of Damino acids from DL-amino acids was carried out under the same conditions as the $\mathrm{L}$-amino acid oxidation using 100 micromoles of DL-amino acids in $1 \mathrm{ml}$ of reaction mixture.
2.5. Determination of $\mathrm{D}-$ and $\mathrm{L}-$ Amino Acids and Reaction Product of L-Amino Acid Oxidation. When L-amino acids were used as substrate, the reaction products were separated from unconverted L-amino acids by HPLC with a TSKgel DEAE-5PW column (Tosoh, Tokyo, Japan) at a flow rate of $0.8 \mathrm{ml}$ per min at $40^{\circ} \mathrm{C}$. In this HPLC analysis, the products were eluted with water for $5 \mathrm{~min}$, followed by increasing the $\mathrm{NaCl}$ concentration to $0.3 \mathrm{M}$ with a linear gradient for $10 \mathrm{~min}$, and then by $0.3 \mathrm{M} \mathrm{NaCl}$ for $10 \mathrm{~min}$. Detection was carried out at $210 \mathrm{~nm}$, and the product amounts were calculated from the peak area.

When a mixture of $\mathrm{D}$ - and $\mathrm{L}$-amino acids was used as substrate, product from L-amino acid oxidation was first separated from D-amino acid and unconverted L-amino acid by HPLC with a TSKgel DEAE-5PW column under the same conditions as above. The fraction containing $\mathrm{D}-$ and $\mathrm{L}-$ amino acids was then applied to HPLC with a CROWNPAK $\mathrm{CR}(+)$ (Daicel Chemical Industries, Tokyo, Japan). This HPLC analysis was carried out at a flow rate of $0.5 \mathrm{ml} / \mathrm{min}$ at $25^{\circ} \mathrm{C}$ using a $\mathrm{HClO}_{4}$ solution, $\mathrm{pH} 1.0-2.0$. Detection was carried out at $200 \mathrm{~nm}$, and amounts of D-amino acid and unconverted $\mathrm{L}$-amino acid were calculated from the peak area from HPLC.

2.6. Identification of Reaction Product from L-Amino Acid Oxidation. Each reaction product from L-amino acids oxidation, which was obtained by HPLC with a TSKgel DEAE5PW column, was concentrated by a SpeedVac concentrator, and then applied to HPLC with a CynProPep C18 column (Shimadzu, Kyoto, Japan). The eluate was concentrated again by a SpeedVac concentrator and applied to an HCT Ultra mass spectrometric instrument (Bruker Daltonics $\mathrm{GmbH}$, Bremen, Germany). Sample was identified by electrospray ionization (ESI-) mass spectrometry (MS) or ESI-MS/MS. The electrospray ionization voltage of the capillary was set to $-4500 \mathrm{~V}$ and the end plate to $-500 \mathrm{~V}$. Nitrogen was used as dry gas at a temperature of $300^{\circ} \mathrm{C}$ and a flow rate of $10 \mathrm{l} / \mathrm{min}$. MS and MS/MS spectra were collected over a $\mathrm{m} / \mathrm{z}$ range of $50-300$ at $8,100 \mathrm{~m} / \mathrm{zs}-1$.

\section{Results}

3.1. Effects of pH on L-Amino Acid Oxidation and Enzyme Stability. Effects of $\mathrm{pH}$ on L-amino acid oxidation were assayed using $2.21 \times 10^{-3} \mathrm{U}$ of L-AAO under standard assay conditions of enzyme activity measurement, except that the reaction $\mathrm{pH}$ values and $\mathrm{L}$-amino acids were varied. The optimum $\mathrm{pH}$ of oxidase activity for acidic amino acids such as L-glutamic acid and L-aspartic acid ranged 8.0-8.5, and the activity at $\mathrm{pH} 6.0$ was less than $30 \%$ of that at $\mathrm{pH}$ 8.5. These results were similar to those of $N \alpha$-Z-L-lysine. In contrast, the optimum $\mathrm{pH}$ of oxidase activity for $\mathrm{L}$-lysine and all other L-amino acids tested was $\mathrm{pH}$ 5.5-6.0 and $\mathrm{pH} 7.0$ 7.5 , respectively, and their respective activities between $\mathrm{pH}$ 5.5 and 8.5 accounted for more than $60 \%$ of the optimum activity (Figure 1).

To analyze its $\mathrm{pH}$ stability, $\mathrm{L}-\mathrm{AAO}$ was incubated at $40^{\circ} \mathrm{C}$ for $60 \mathrm{~min}$ in the $\mathrm{pH}$ region between 5.0 and 8.5, and the 


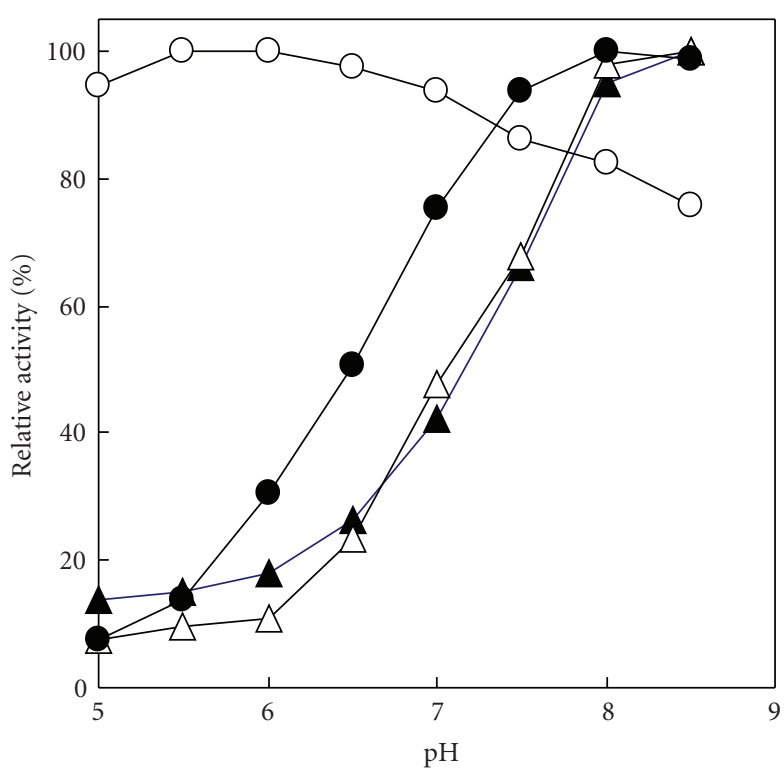

(a)

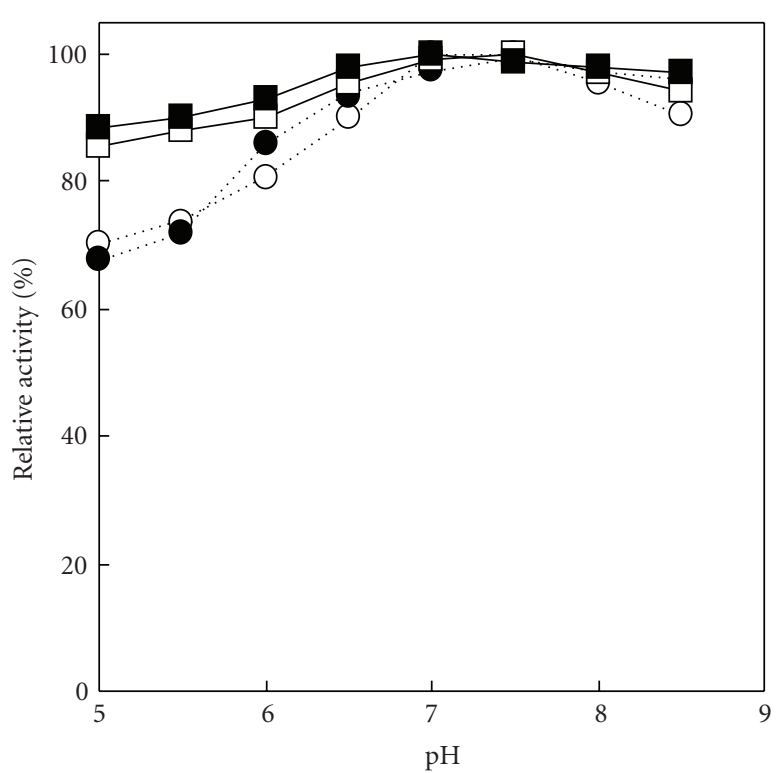

(b)

FIGURE 1: Effect of reaction $\mathrm{pH}$ on $\mathrm{L}$-amino acid oxidation. The reaction was carried out under standard reaction conditions, except that the reaction $\mathrm{pH}$ values were varied between $\mathrm{pH} 5.0$ and 8.5 , using $0.1 \mathrm{mmol}$ of acetate buffer, $\mathrm{pH} 5.0-5.5$ and 0.1 mmol of potassium phosphate, pH 5.5-8.5. The following L-amino acids were used as substrate. (a) Open circles, L-lysine; closed circles, N $\alpha$-Z-L-lysine; open triangles, Laspartic acid; closed triangles, L-glutamic acid. (b) Open squares (solid line), L-leucine; closed squares (solid line), L-ornithine; open circles (dotted line), L-asparagine; closed circles (dotted line), L-homoserine.

TABle 1: Analysis of oxidation products from L-amino acids. Twenty micromoles of each L-amino acid was incubated with $15.5 \times 10^{-3} \mathrm{U}$ of L-AAO under standard conditions of L-amino acid oxidation, and the reaction mixture was applied to HPLC with a TSKgel DEAE-5PW column. Molecular mass of reaction products was analyzed by an HCT Ultra mass spectrometric instrument.

\begin{tabular}{lccl}
\hline L-Amino acid & \multicolumn{2}{c}{ Elution time (min) } & Reaction product \\
& L-Amino acid & Products & Molecular mass (product name) \\
\hline L-Homoserine & 3.3 & 15.8 & 118.1 (2-oxo-4-hydroxybutyric acid) \\
L-Leucine & 3.2 & 18.3 & 130.0 (2-oxo-4-methylvaleric acid) \\
L-Lysine & 2.7 & 4.8 & 145.1 (2-oxo-6-aminohexanoic acid) \\
L-Glutamine & 3.3 & 15.1 & 145.1 (2-oxo-4-carbamoylbutanoic acid) \\
L-Arginine & 2.3 & 3.3 & 173.1 (2-oxo-5-guanidinopentanoic acid) \\
L-Glutamic acid-Na & 14.6 & 18.5 & 190.0 (2-oxoglutaric acid) \\
L-Citrulline & 3.2 & 14.9 & 174.0 (2-oxo-5-ureidovaleric acid) \\
& 3.5 & 15.8 & 174.0 (pyrrolidine-1-carbamyl-2-hydroxy-2-carboxylic acid) \\
L-Phenylaranine & 24.9 & 164.1 (2-oxo-3-phenylpropionic acid) \\
L-Histidine & 3.0 & 17.9 & 154.3 (2-oxo-4-imidazolepropionic acid) \\
NE-Acetyl-L-lysine & 3.2 & 15.5 & 187.1 (2-oxo-6-acetylaminohexanoic acid) \\
\hline
\end{tabular}

residual activities were assayed. The enzyme was stable in the $\mathrm{pH}$ region between 6.0 and 8.0 (data not shown). When this enzyme was incubated at $30-60^{\circ} \mathrm{C}$ for $60 \mathrm{~min}$ at $\mathrm{pH} 7.0$, approximately $80 \%$ of the enzyme activity remained at $40^{\circ} \mathrm{C}$, although the enzyme activity was almost completely lost at $50^{\circ} \mathrm{C}$ (Figure 2). On the basis of the optimum reaction $\mathrm{pH}$ and $\mathrm{pH}$ stability, the following studies were carried out at $\mathrm{pH}$ 7.0 and $30^{\circ} \mathrm{C}$.

3.2. Identification of Products from $\mathrm{L}$-Amino Acid Oxidation. Each L-amino acid indicated in Table 1 was incubated with $15.5 \times 10^{-3} \mathrm{U}$ of $\mathrm{L}-\mathrm{AAO}$ under standard conditions of L-amino acid oxidation, and the reaction mixture was applied to HPLC with a TSKgel DEAE-5PW column. In this HPLC analysis, a new single peak was obtained from Lhomoserine, L-leucine, L-lysine, L-glutamine, L-arginine, Lglutamic acid, L-phenylalanine, L-histidine and $N \mathcal{E}$-acetyl-Llysine (Table 1), and the keto-group was confirmed in the compound of each peak. In addition, the molecular mass of the peak compounds was coincident with the theoretical value of $\alpha$-keto-acid corresponding to the $\mathrm{L}$-amino acid. In the case of L-citrulline, two peaks were newly obtained by HPLC with a TSKgel DEAE-5PW column (Table 1). When 


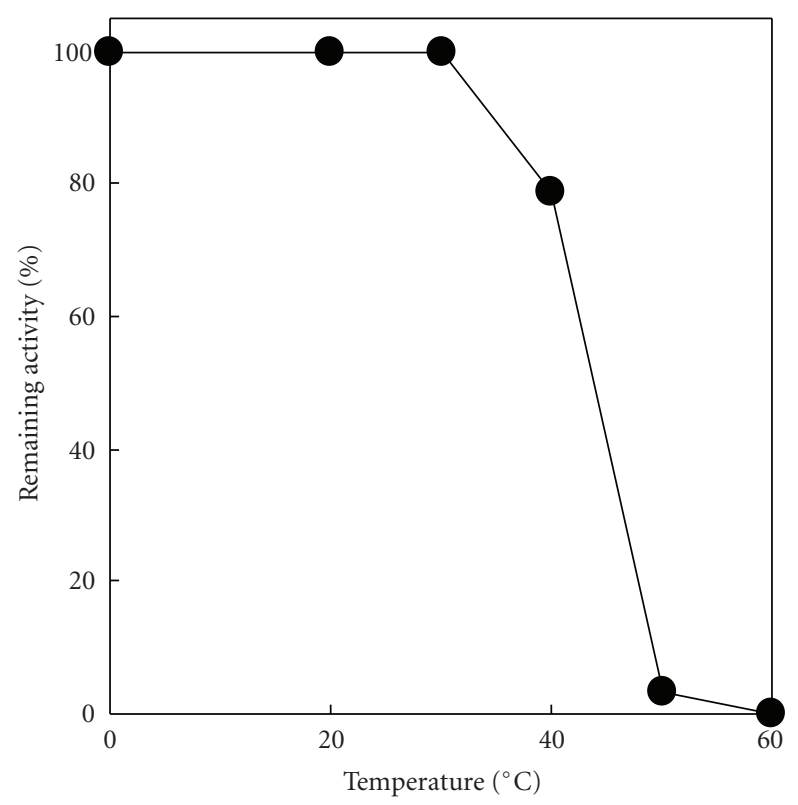

Figure 2: Effect of temperature on enzyme stability. The enzyme

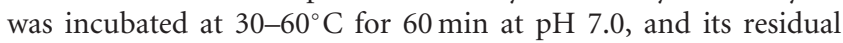
activity was assayed under standard assay condition of enzyme activity.

the compound of each peak was applied again to the same column, two peaks were also obtained from each compound at the same elution time, indicating that the oxidative products from $\mathrm{L}$-citrulline are in a state of equilibrium. The molecular mass of both compounds was also coincident with the theoretical value of the corresponding $\alpha$-keto-acid of L-citrulline (Table 1). Thus, it was presumed that one product from L-citrulline is 2-oxo-5-ureidovaleric acid and the other is pyrrolidine-1-carbamyl-2-hydroxy-2-carboxylic acid. These results experimentally supported our previous report that L-AAO from Rhodococcus Z-35-1 is L-specific amino acid oxidase with broad substrate specificity [16]. They also indicate that the above L-amino acids were converted to the corresponding $\alpha$-keto-acids by the oxidative deamination of the $\alpha$-amino group of L-amino acids.

3.3. L-Amino Acid Oxidation. Since enantioselective production of D-amino acids from DL-amino acids is achieved by the complete oxidation of L-amino acids, we investigated the optimum enzyme amounts for complete oxidation of L-amino acids under standard conditions using L-amino acids which are not substrates of D-aminoacylases, Dhydantoinases and D-amino acid amidases. When $20 \mathrm{mM}$ of L-citrulline, L-glutamine, L-homoserine, L-leucine or $N \mathcal{E}$ acetyl-L-lysine was incubated with $15.5 \times 10^{-3} \mathrm{U}$ of $\mathrm{L}-\mathrm{AAO}$ at $\mathrm{pH} 7.0$ and $30^{\circ} \mathrm{C}$, those amino acids were completely converted to the corresponding $\alpha$-keto-acids within $24 \mathrm{hr}$ (data not shown). In the respective case of $\mathrm{L}$-arginine, $\mathrm{L}$ glutamic acid, L-phenylalanine, and L-histidine, 95\%, 87\%, $85 \%$ and $79 \%$ of the original amounts were converted to the corresponding $\alpha$-keto-acids, respectively, under the same conditions (data not shown). The enzyme amounts for complete oxidation of $50 \mathrm{mM} \mathrm{L}$-amino acids were further analyzed. L-Citrulline, L-homoserine, L-glutamine, L-leucine or $N \mathcal{E}$-acetyl-L-lysine required $45 \times 10^{-3} \mathrm{U}$ of $\mathrm{L}$-AAO for complete oxidation within $24 \mathrm{hr}$. For L-arginine, L-glutamic acid, L-phenylalanine or L-histidine, $60 \times 10^{-3} \mathrm{U}$ of $\mathrm{L}^{-}$ AAO were required for complete oxidation within $24 \mathrm{hr}$. These results indicate that high concentration of L-amino acids and the reaction products do not inhibit the L-amino acid oxidation. They also indicate that enzyme amounts for complete oxidation of L-amino acids might be calculated in light of the present results and the relative reaction rate shown in [16].

3.4. Enzymatic Resolution of DL-Amino Acids. On the basis of the above results of the complete oxidation of L-amino acids, D-amino acid production was investigated using DL-amino acids as substrate. When $100 \mathrm{mM}$ each of DL-citrulline, DL-glutamine, DL-homoserine or $N \mathcal{E}$-acetyl-DL-lysine was incubated with $40 \times 10^{-3} \mathrm{U}$ of L-AAO, the L-amino acids were oxidized to the corresponding $\alpha$-keto-acids within 24 $\mathrm{hr}$ of incubation, and $\mathrm{D}$-amino acids remained without any reaction (Figure 3 ). When $100 \mathrm{mM}$ DL-arginine was incubated with $60 \times 10^{-3} \mathrm{U}$ of $\mathrm{L}$-AAO, L-arginine was also completely oxidized, but $\mathrm{D}$-arginine was not (data not shown).

\section{Discussion}

At present, a wide variety of D-amino acids cannot be produced by one enzyme system, because presently available enzymes have a limited substrate specificity. Recently, we found a new L-AAO from Rhodococcus sp. AIU Z-35-1, which catalyzed oxidative deamination of constituent and nonconstituent L-amino acids of natural proteins. Therefore, we developed a new simple enzymatic method for production of a wide variety of $\mathrm{D}$-amino acids from a racemic mixture by kinetic resolution using L-AAO from Rhodococcus sp. AIU Z-35-1. Firstly, we analyzed the optimum conditions for Lamino acid oxidation. When the $\alpha$-amino group of L-lysine was covered with the benzyloxicarbonyl-group, optimum $\mathrm{pH}$ changed to $8.0-8.5$. This $\mathrm{pH}$ range is similar to that of acidic amino acids such as L-glutamic acid and L-aspartic acid, suggesting that the optimum $\mathrm{pH}$ of $\mathrm{L}$-amino acid oxidation is affected by the amino group of L-amino acids. Our studies of optimum $\mathrm{pH}$ also showed that the enzyme activity at $\mathrm{pH}$ 7.0 accounts for more than $60 \%$ of the optimum activity in L-amino acid oxidation tested. In addition, the enzyme was stable at $\mathrm{pH}$ 7.0. Therefore, we concluded that incubation at $\mathrm{pH} 7.0$ is optimum for $\mathrm{D}$-amino acid production by kinetic resolution using our L-AAO. Under the optimum conditions, some $\mathrm{D}$-amino acids, which are difficult to produce by $\mathrm{D}$ aminoacylases, D-hydantoinases or D-amino acid amidases, are efficiently produced, since high concentration of $\mathrm{D}$ amino acids, L-amino acids and the reaction products do not inhibit the L-amino acid oxidation, although two oxidative products in the equilibrium state are produced from Lcitrulline. Since it has been already demonstrated that $\mathrm{L}^{-}$ AAO from Rhodococcus sp. AIU Z-35-1 is specific to L-amino 


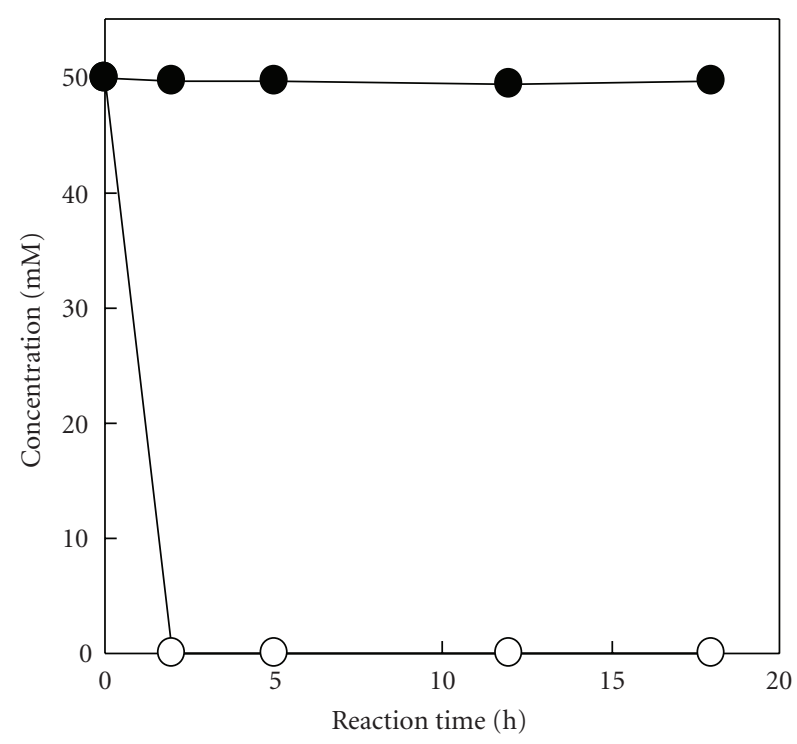

(a)

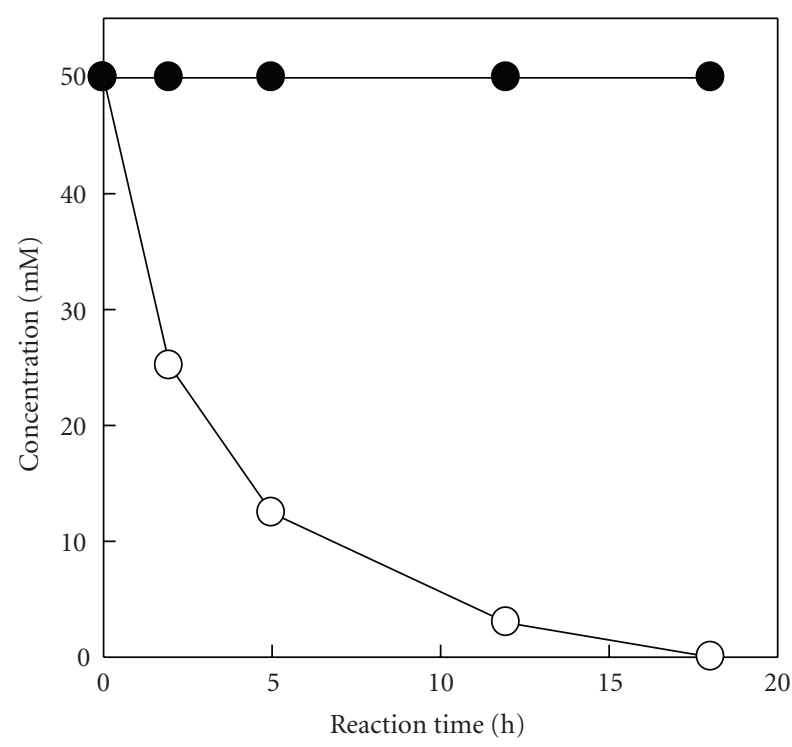

(c)

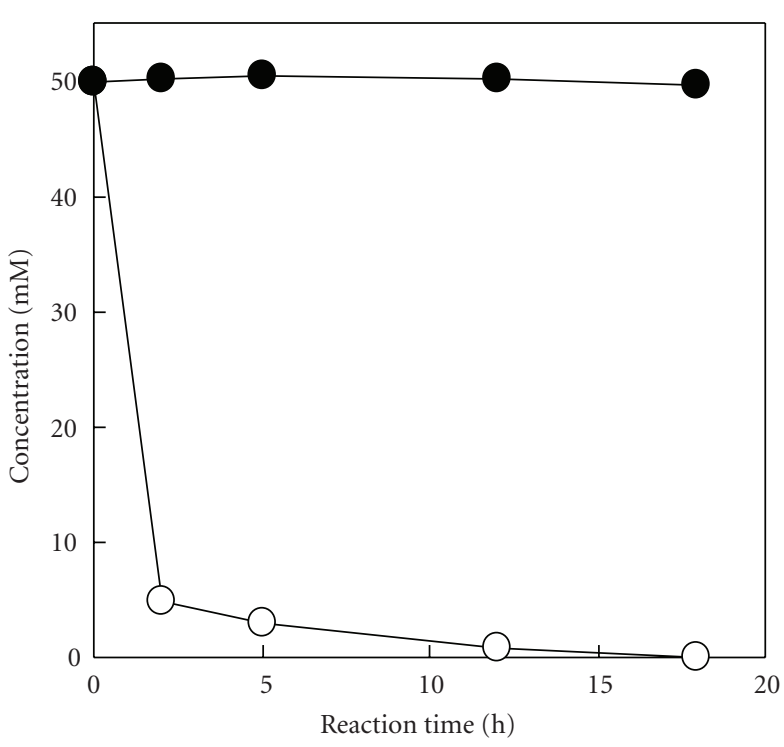

(b)

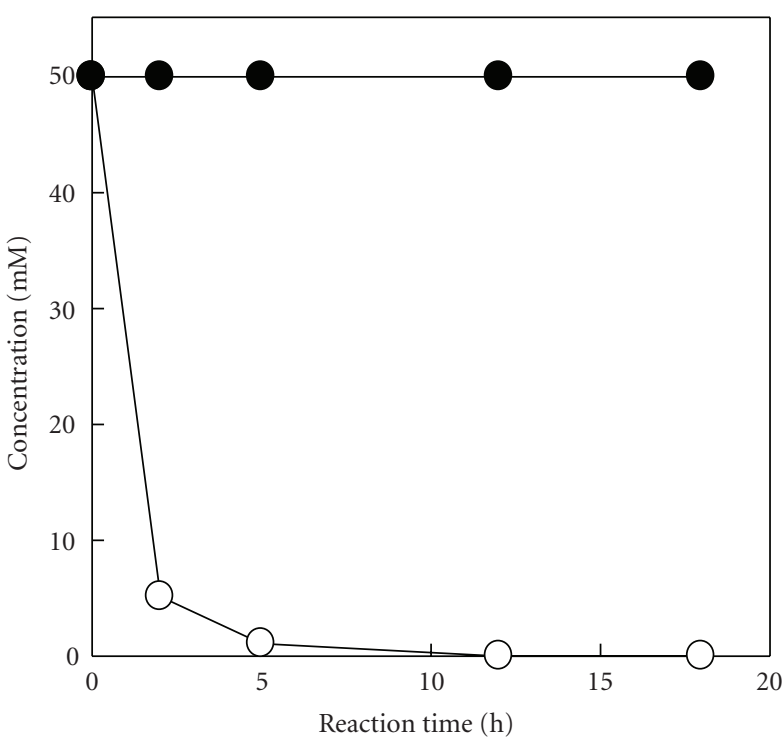

(d)

FIGURE 3: Production of D-amino acid. Approximately $100 \mathrm{mM}$ of DL-homoserine (a), DL-glutamine (b), DL-citrulline (c) or NE-acetyl-DLlysine (d) was incubated at $30^{\circ} \mathrm{C}$ for $24 \mathrm{hr}$ under standard condition of D-amino acid production using $40 \times 10^{-3} \mathrm{U}$ of $\mathrm{L}$-AAO. DL-Amino acids of reaction mixture were first separated from the reaction products by HPLC with a TSKgel DEAE-5PW column, and each D- and L-amino acid amount was analyzed by HPLC with a CROWNPAK CR $(+)$ according to the method described in Section 2 . Closed circles, D-amino acids; open circles, L-amino acids.

acids and has broad substrate specificity [16], the present enzymatic method is also useful for production of other $\mathrm{D}$ amino acids.

The enzymatic method developed here has an advantage in that a wide variety of D-amino acids can be produced, although it also has a disadvantage in that the maximum yield of D-amino acids is theoretically $50 \%$ of the DL-amino acids used as a substrate. A further advantage of the new enzymatic method is that it is applicable for the production of keto-acids corresponding to L-amino acids used as substrate. Geueke and Hummel have reported that R. opacus
DSM 43250 produced a new bacterial L-AAO with broad substrate specificity [17]. However, L-AAO of R. opacus is not advantageous for production of a high concentration of D-amino acids, since the enzyme was strongly inhibited by a low concentration of $\mathrm{L}$-amino acids. The $\mathrm{L}$-amino acid deaminases also catalyze the conversion of $\mathrm{L}$-amino acid to the corresponding $\alpha$-keto acids without formation of $\mathrm{H}_{2} \mathrm{O}_{2}$. Therefore, the L-amino acid deaminases are also useful for enantioselective production of $\mathrm{D}$-amino acids from a racemic mixture. However, the substrate specificity of the L-amino acid deaminases reported $[18,19]$ is narrow compared to that 
of L-AAO from Rhodococcus sp. Z-35-1. Thus, L-AAO from Rhodococcus sp. Z-35-1 is the most versatile for enzymatic production of a wide variety of $\mathrm{D}$-amino acids or keto-acids corresponding to L-amino acids from DL-amino acids.

\section{References}

[1] H. Nanba, Y. Ikenaka, Y. Yamada, K. Yajima, M. Takano, and S. Takahashi, "Isolation of Agrobacterium sp. strain KNK712 that produces $N$-carbamyl-D-amino acid amidohydrolase, cloning of the gene for this enzyme, and properties of the enzyme," Bioscience, Biotechnology, and Biochemistry, vol. 62, no. 5, pp. 875-881, 1998.

[2] Y. Ikenaka, H. Nanba, Y. Yamada, K. Yajima, M. Takano, and S. Takahashi, "Screening, characterization, and cloning of the gene for $\mathrm{N}$-carbamyl-D-amino acid amidohydrolase from thermotolerant soil bacteria," Bioscience, Biotechnology and Biochemistry, vol. 62, no. 5, pp. 882-886, 1998.

[3] H. Nanba, T. Nakai, Y. Yasohara, S. Morikawa, and J. Hasegawa, "Development of new bioreactor systems and their applications in the chiral industry," Journal of Synthetic Organic Chemistry, vol. 62, no. 11, pp. 1102-1112, 2004.

[4] M. Moriguchi, K. Sakai, Y. Miyamoto, and M. Wakayama, "Production, purification, and characterization of Daminoacylase from Alcaligenes xylosoxydans subsp. xylosoxydans A-6," Bioscience, Biotechnology, and Biochemistry, vol. 57, no. 7, pp. 1149-1152, 1993.

[5] P.-H. Lin, S.-C. Su, Y.-C. Tsai, and C.-Y. Lee, "Identification and characterization of a new gene from Variovorax paradoxus Isol encoding $N$-acyl-D-amino acid amidohydrolase responsible for D-amino acid production," European Journal of Biochemistry, vol. 269, no. 19, pp. 4868-4878, 2002.

[6] M. Wakayama, K. Yoshimune, Y. Hirose, and M. Moriguchi, "Production of D-amino acids by $N$-acyl-D-amino acid amidohydrolase and its structure and function," Journal of Molecular Catalysis B: Enzymatic, vol. 23, no. 2-6, pp. 71-85, 2003.

[7] S. Kumagai, M. Kobayashi, S. Yamaguchi, T. Kanaya, R. Motohashi, and K. Isobe, "A new D-aminoacylase from Defluvibacter sp. A 131-3," Journal of Molecular Catalysis B: Enzymatic, vol. 30, no. 3-4, pp. 159-165, 2004.

[8] Y. Asano and S. Yamaguchi, "Dynamic kinetic resolution of amino acid amide catalyzed by $\mathrm{D}$-aminopeptidase and $\alpha$-amino-E-caprolactam racemase," Journal of the American Chemical Society, vol. 127, no. 21, pp. 7696-7697, 2005.

[9] H. Komeda, N. Ishikawa, and Y. Asano, "Enhancement of the thermostability and catalytic activity of D-stereospecific amino-acid amidase from Ochrobactrum anthropi SV3 by directed evolution," Journal of Molecular Catalysis B: Enzymatic, vol. 21, no. 4-6, pp. 283-290, 2003.

[10] T. Hongpattarakere, H. Komeda, and Y. Asano, "Purification, characterization, gene cloning and nucleotide sequencing of D-stereospecific amino acid amidase from soil bacterium: Delftia acidovorans," Journal of Industrial Microbiology and Biotechnology, vol. 32, no. 11-12, pp. 567-576, 2005.

[11] H. Komeda and Y. Asano, "A novel D-stereoselective amino acid amidase from Brevibacterium iodinum: gene cloning, expression and characterization," Enzyme and Microbial Technology, vol. 43, no. 3, pp. 276-283, 2008.

[12] M. Yagasaki, M. Azuma, S. Ishino, and A. Ozaki, "Enzymatic production of D-glutamate from L-glutamate by a glutamate racemase," Journal of Fermentation and Bioengineering, vol. 79, no. 1, pp. 70-72, 1995.
[13] M. Yagasaki and A. Ozaki, "Industrial biotransformations for the production of D-amino acids," Journal of Molecular Catalysis B: Enzymatic, vol. 4, no. 1-2, pp. 1-11, 1998.

[14] K. Mochizuki and K. Miyazaki, "Microbial resolution of DLhomoserine for the production of D-homoserine using a novel isolate, Arthrobacter nicotinovorans strain 2-3," Enzyme and Microbial Technology, vol. 41, no. 3, pp. 318-321, 2007.

[15] K. Isobe, K. Tokuta, Y. Narita, A. Matsuura, T. Sakaguchi, and N. Wakao, "Production of $N^{\alpha}$-benzyloxycarbonyl-Laminoadipic acid and $N^{\alpha}$-benzyloxycarbonyl-D-aminoadipic acid with Rhodococcus sp. AIU Z-35-1," Journal of Molecular Catalysis B: Enzymatic, vol. 32, no. 1-2, pp. 27-32, 2004.

[16] K. Isobe and S. Nagasawa, "Characterization of $N^{\alpha}-$ benzyloxycarbonyl-L-lysine oxidizing enzyme from Rhodococcus sp. AIU Z-35-1," Journal of Bioscience and Bioengineering, vol. 104, no. 3, pp. 218-223, 2007.

[17] B. Geueke and W. Hummel, "A new bacterial L-amino acid oxidase with a broad substrate specificity: purification and characterization," Enzyme and Microbial Technology, vol. 31, no. 1-2, pp. 77-87, 2002.

[18] G. Massad, H. Zhao, and H. L. T. Mobley, "Proteus mirabilis amino acid deaminase: cloning, nucleotide sequence, and characterization of aad," Journal of Bacteriology, vol. 177, no. 20, pp. 5878-5883, 1995.

[19] D. P. Pantaleone, A. M. Geller, and P. P. Taylor, "Purification and characterization of an L-amino acid deaminase used to prepare unnatural amino acids," Journal of Molecular Catalysis B: Enzymatic, vol. 11, no. 4-6, pp. 795-803, 2001. 

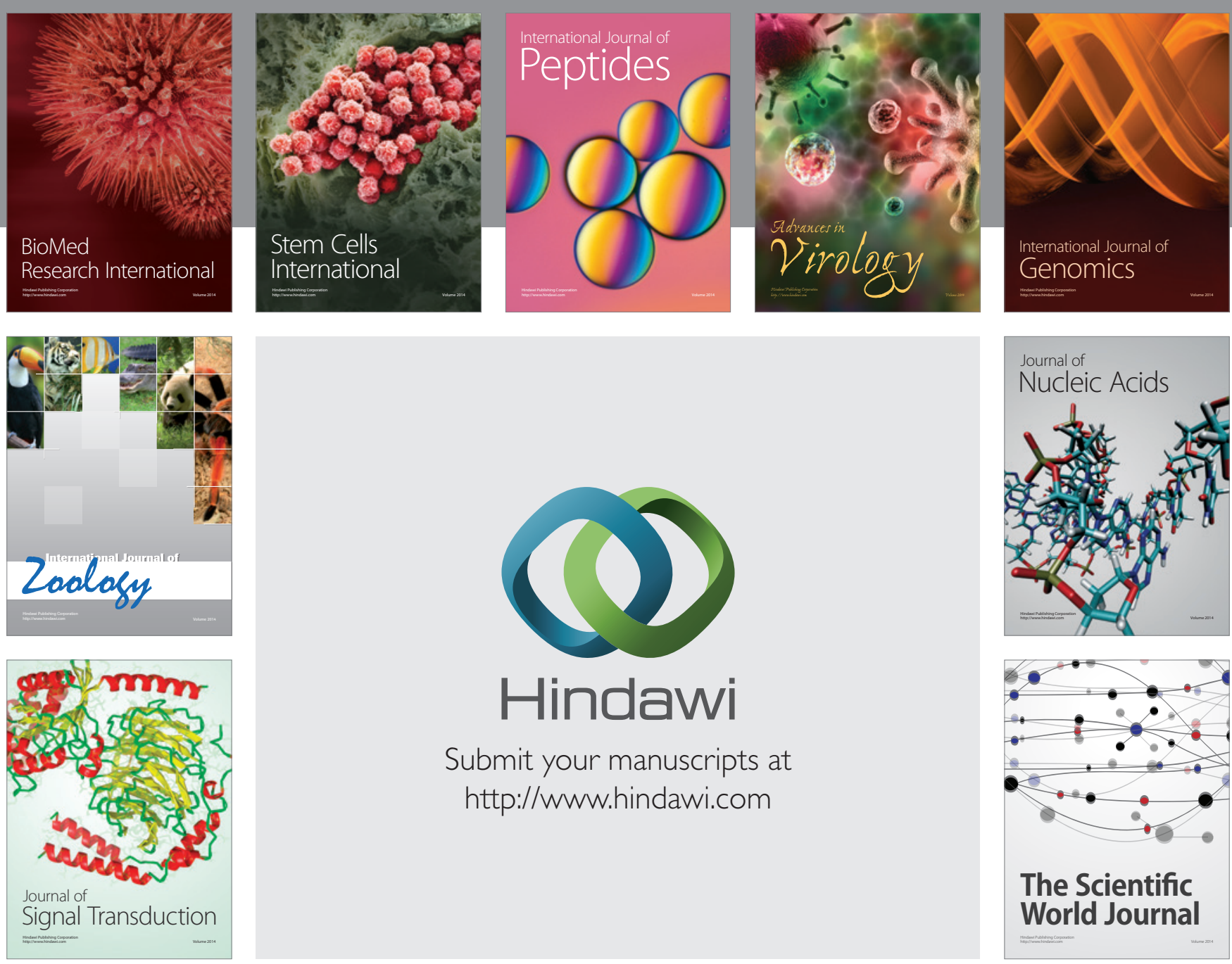

Submit your manuscripts at

http://www.hindawi.com
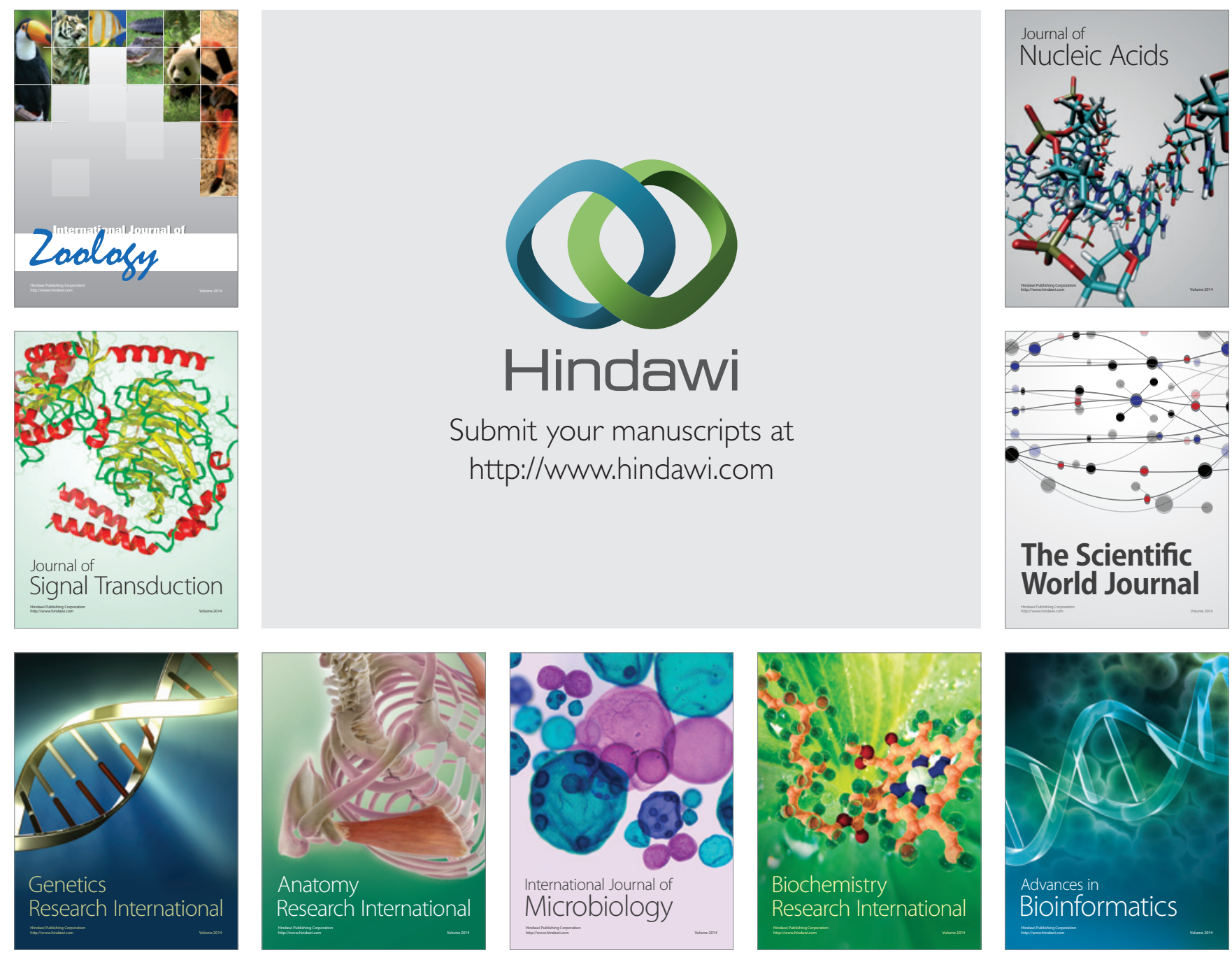

The Scientific World Journal
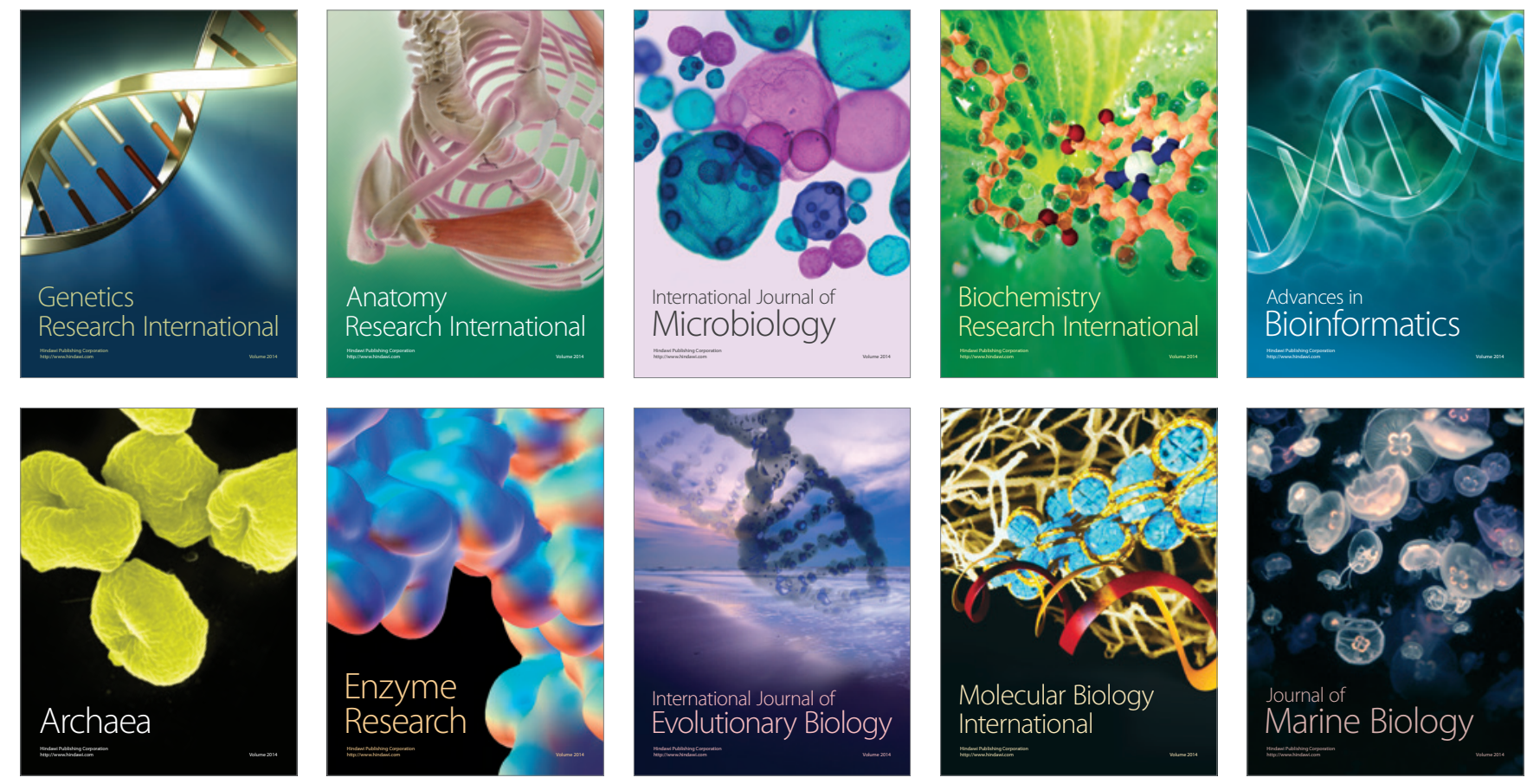